\title{
Leadership Style and Business Performance in Nepali SMEs: The Mediating Role of Entrepreneurship Orientation
}

\author{
Samundra Paudel (PhD Scholar)* \\ Faculty of Management, Tribhuvan University, Kritipur, Nepal
}

\begin{abstract}
Leadership and entrepreneurship, and their effects on business performance are major issues in contemporary academic research as they are linked with economic development of a nation. However, relatively only a few studies have been carried out on the relationship among these three variables with even less attention paid to entrepreneurship orientation (EO) serving as a mediator in leadershipperformance relationship. This study firstly tested the relationship between leadership style and business performance and then analyzed the mediating role of EO between them in the Nepali SMEs. The study utilized 188 responses collected from business owners in Pokhara, Nepal. Findings suggest that transformational and transactional leadership style as well as EO exert significant positive influence over business performance. The study indicates that transformational leadership is stronger predictor of EO and business performance than transactional leadership style. It also found that EO mediates transformational leadership-performance relationship. The implications, limitations, and suggestions have been identified and discussed.
\end{abstract}

Keywords: Entrepreneurship orientation, leadership style, business performance, Nepali SMEs

\section{Introduction}

Entrepreneurship, which received renewed attention of academia since 1990s, is considered important for economic development of a nation (Wennekers \& Thurik, 1999). Entrepreneurs drive an economy through technological progress, creation of new firms and jobs, and generation of additional output to entire economy. They envision future possibilities, take risk, exploit opportunities through innovation and pro-activeness, and transform their organization to higher level (Covin \& Slevin, 1991; Gupta, MacMillan, \& Suriec, 2004). An entrepreneur as a leader inspires group members and employs them in a desired manner to accomplish goals and business possibilities (Bass, 2008). The entrepreneur's leadership styles and firm's entrepreneurial orientation (EO) are considered important components of entrepreneurial processes. Though most of the researches largely analyzed entrepreneurship and leadership separately, some studies explored that leadership style, EO and business performance are related with each other (Gupta et al., 2004; Yang, 2008). Thus, the interrelationship among leadership and entrepreneurship orientation as well as their effects on business performance evolved as major issue in contemporary research (Yang, 2008). The researchers also recognized the mediating role of

* Author Email: paudelsamu@gmail.com 
EO between leadership and performance. However, very few studies examined EO as a mediator in this relationship (Arham, 2012) indicating its poor reception of scholarly inquiry.

Furthermore, entrepreneurship and especially in the SMEs which are significant for economic and social phenomena in the world, are the least studied in developing countries (Arham, 2012; Paudel, 2019). Moktan (2007) stated that in South Asia, the SMEs constituted over 97 percent of total businesses, contributed between 40-60 percent of the total output to their national economies and account over 70 percent of total employment. In Nepal, the SMEs comprised almost 95-98 percent of the total business establishments and contributed 83 percent in employment generation (Pandey, 2004). Though significant role of the Nepali SMEs in the economic activities along with different institutions working rigorously for their betterment, they were unable to generate as much growth as they could have ((Ghimire, 2011), MoF, 2017). For last few years, industrial and trading sectors' contribution in national GDP had been rapidly decreasing and the SMEs' failure rate was alarmingly high (MoF, 2017). Moreover, interest and trends on entrepreneurship development as well as related research have not been growing in Nepal compared to increasing interest to study them worldwide. Some studies have been conducted on women entrepreneurship (Bushell, 2008; Tuladhar, 1996), microenterprises (Villanger, 2015), and other entrepreneurship issues (Pant, 2015; Parker, 1988; Shrestha, 2015) in Nepali context. But only a few studies analyzed the impact of leadership style on work unit and organizational performance and even less examined EO-performance relationship (Shrestha, 2012; Uprety, 2016). Gautam (2016) revealed that Nepali handicrafts industry owners had low level of EO in comparison to other countries. Paudel (2019) also explored that low business performance due to owners' lack of required skills (e.g., entrepreneurial and leadership) were the reasons behind their failures. Thus, low level of EO and inappropriate leadership style might be the important reasons for low performance and failures of the Nepali SMEs. However, no studies are available that have investigated the effects of leadership styles and EO together on business performance indicating the contextual need to study this relationship.

Therefore, this research attempted to identify the effects of leadership styles and EO on business performance. Analyzing additional scholarly gap and contextual need as discussed above, it also examined the mediating effect of EO between the leadership styles and business performance relationship.

\section{Leadership and Leadership Style}

\section{Theoretical Background}

Leadership provides vision and direction towards goal attainment. Yukl (2013) defined leadership as "the process of influencing others to understand and agree about what needs to be done and how it can be done effectively, and the process of facilitating individual and collective efforts to accomplish the shared objectives" (p.7). Leadership is a capability aimed at achieving organizational targets affecting all organizational activities (Stogdill, 1948). Effective leadership style plays an important role for better performance of any organization. Contemporary literature on leadership focuses on the three major leadership styles i.e. transformational, transactional, and laissez faire (non-leadership) (Bass, 2008).

Transformational leaders are proactive, create emotional relationship with followers, encourage followers to put extra efforts and change organizational environment. This leadership style appeals followers toward higher levels of organizational commitment and performance (Yukl, 2013). Idealized influence, inspirational motivation, intellectual stimulation, and individualized consideration are four dimensions of transformational leadership (Bass, 2008). Idealized influence is the degree to which 
leader act as their role model, instills pride, gains trust, and appeals to followers' hopes and dreams (Arham, 2012). Inspirational motivation indicates the degree to which leader provides vision, communicates optimism, provides meaning for the task and try to make others feel their work as significant which further inspire followers (Bass, 2008). Intellectual stimulation indicates the degree to which leader challenges assumptions, encourages followers to be more creative in solving old problems in new ways, and nurtures and develops followers to think independently (Arham, 2012). Individualized consideration refers to the degree to which leader listens followers' concerns, interest and well-being, gives empathy, and supports to each individual for their self-development which increase follower's intrinsic motivation for their task (Bass, 2008).

Transactional leaders are reactive and focus mainly on material relationships with followers (Bass, 2008). They clarify roles and requirements, reward desired performance, and focus on immediate selfinterest of followers (Northouse, 2010; Yukl, 2013). Contingent reward and management-by-exception are two dimensions of transactional leadership (Bass, 2008). Contingent reward indicates the degree to which leader clarifies expectations, establishes rewards for meeting expectations, and compensates for their accomplishments (Arham, 2012). Management-by-exception refers to the leader setting minimum standards for compliance and ineffective performance, monitoring follower's behavior and acts, and punishing followers for non-compliance with the standards (Bass, 2008). A final form of leadership, actually non-leadership is passive-avoidant (laissez-faire) leadership. Laissez faire leaders are passive in their nature, avoid taking decisions, hesitate making actions, absent when needed as well as feel comfortable to any ongoing activities in organization and let others do things in their way (Bass, 2008).

\section{Entrepreneurship Orientation (EO)}

Millar introduced the concept of EO for the first time in 1983 (Covin \& Slevin, 1991). He has suggested that an entrepreneurial firm engages in proactive behavior, comes up with product, processes and marketing innovation, undertakes somewhat risky ventures, and beats its competitors. Covin and Slevin (1991) specified EO as firm's strategic orientation in relation to innovativeness, pro-activeness, and risk-taking.

The innovativeness reflects the tendency of the firm to new ideas and creative process that may result in new products, services, or technological processes (Wiklund \& Shepherd, 2005). Proactiveness refers to opportunity-seeking and forward-looking perspective of the firm. It is like introducing new products and services ahead of the competition and showing aggressive behavior directed to its rival firms (Covin \& Slevin, 1991). Risk-taking is the propensity to take bold actions and committing large resources on risky projects (Covin \& Slevin, 1991).

Lumpkin and Dess (1996) extended EO to five dimensions, autonomy and competitive aggressiveness including original risk-taking, pro-activeness, and innovation. Many researchers have agreed that innovation, pro-activeness, and risk-taking could explain EO (Smart \& Conant, 1994; Wiklund \& Shepherd, 2005).

\section{Business Performance}

Business performance refers to firm's ability to achieve goals like quality product, increased market share, superior financial results, high profit, and survival within a certain period of time (Koontz \& Donnell, 1993). Covin and Slevin (1991) outlined that profitability and growth are the primary dimensions of business performance. In the entrepreneurship research, growth, efficiency, and profitability are the most commonly used performance evaluation dimensions (Murphy, Trailer, \& 
Hill, 1996). It's been postulated that growth positively influences profitability (Markman \& Gartner, 2002). Wiklund and Shepherd (2005) also argued that performance measures should include growth as the SMEs may be reluctant to provide actual financial performance figures as it does not legally require them to publicize it.

\section{Relationship between Leadership Style and Business Performance}

Both transformational and transactional leadership styles positively influence organizational performance and leadership effectiveness (Bass, 2008). After studying 406 SMEs , Yang (2008) concluded that both leadership styles were significantly positively correlated with business performance. A study from a Nepali context also has indicated both leadership styles were positively related with leadership effectiveness and outcomes (Shrestha, 2012).

While comparing two styles; transformational leadership is more strongly correlated to higher performance and productivity than transactional leadership has with them (Bass, 1985). Yang (2008) confirmed that different leadership styles might affect business performance highlighting the transformational leadership to be more correlated to performance. In the context of developing countries too, leadership style has a direct impact on business performance, with transformational leadership having the stronger impact in comparison with transactional leadership (Arham, 2012). In Nepal, it was found that transformational leadership was the strong predictor of leader and work-unit effectiveness than transactional leadership (Shrestha, 2012). In line with these findings, it is proposed that:

H1A: Transformational leadership has significant and positive effect on business performance.

H1B: Transactional leadership has significant and positive effect on business performance.

H1C: Transformational leadership has a greater and more positive effect on the business performance compared to transactional leadership.

\section{Relationship between Entrepreneurship Orientation and Business Performance}

EO has been regarded as an important characteristic of high performing business (Covin \& Slevin, 1991; Lumpkin \& Dess, 1996). Covin and Slevin (1991) argued that only those firms that displayed excellent performance in the three dimensions (innovativeness, pro-activeness, and risk-taking) of EO were considered as entrepreneurial. Past researches have shown that EO positively influences business performance (Covin \& Slevin, 1991; Smart \& Conant, 1994; Yang, 2008; Zahra, 1991). Wiklund and Shepherd (2005) based on 413 Swedish SMEs, investigated the effects of EO dimensions (innovativeness, risk-taking, and pro-activeness) on firms' performance and found positive impacts.

Fairoz, Hirobumi, and Tanaka (2010) also explored that the firms with higher EO had higher sales growth, profit, and market share than firms with lower EO. Smart and Conant (1994) concluded that firms with higher EO had better performance outcomes than firms with lower and medium EO. Meta analyses based on 51 studies with 14,259 sample firms have reported moderately large $(\mathrm{r}=.242)$ correlation between EO and performance and argued that this relationship was robust to different operationalizations of key constructs as well as cultural contexts (Rauch, Wiklund, Lumkin, \& Frese, 2004). Gautam (2016), who investigated the relationship between EO and performance based on 161 Nepali handicrafts enterprises, found that EO positively influenced business performance. Based on above evidences, it is postulated that:

H2: Entrepreneurship Orientation has significant positive effect on business performance. 


\section{Relationship between Leadership Style and Entrepreneurship Orientation}

The type of leadership style displayed by the owner could help foster entrepreneurial behaviors within the SMEs (Arham, 2012). Eyal and Kark (2004) claimed that transformational leadership was one of the key processes to influence follower and acknowledged it as a basic condition required for the development of radical entrepreneurial approaches. Out of the transformational and transactional leadership skills, Yang (2008) found the first to contribute more significantly to firm's EO than the second one. While analyzing transactional leadership and EO, Eyal and Kark (2004) found no significant relationship between them. Arham (2012) surveyed Malaysian SMEs and found that transformational leadership has a stronger influence on EO than transactional leadership. Based on above observations, it is hypothesized that:

H3: Transformational leadership has more positive and significant effect on entrepreneurship orientation compared to transactional leadership.

\section{Entrepreneurship Orientation as Mediator}

Though limited numbers of researches exist on the mediating role of EO in leadership-business performance relationship, few studies indicated the transformational leadership leading to higher EO which in turn would contribute to higher business performance (Arham, 2012; Yang, 2008). Yang's study in 2008 has indicated mediatory role of EO between leadership style (transformational and transactional) and business performance. Arham (2012) studied relationships between these three variables taking the Malaysian SMEs as sample. The study has found mediation of EO between leadership-performance relationships. In line with these results, it is proposed that:

H4: Entrepreneurship orientation mediates the relationship between transformational leadership and business performance.

H5: Entrepreneurship orientation mediates the relationship between transactional leadership and business performance.

Based on above discussions and hypotheses, a theoretical framework has been developed as shown in figure 1 to depict the role of the EO as mediator in leadership-business performance relationship in the Nepali SMEs.

\section{Methods}

\section{Population}

Population for this research comprised the SMEs operating in Pokhara, Nepal. While the SMEs in Nepal are defined on the basis of the size of investment made on fixed assets (Industrial Policy, 2010), determining the exact number of the SMEs (population) within that category is difficult as different authorities register businesses in Nepal (Ghimire, 2011). Due to this difficulty, Pokhara was selected as the sample location based on its significance in Nepal's economy as 'major tourist destination and prominent business center' (Pant, 2015). For this study, total 2,145 registered members of Pokhara Chamber of Commerce and Industry (PCCI) were assumed as preliminary population. However, the early participants were also requested to suggest other non-member entrepreneurs who would be interested to participate in this study. 


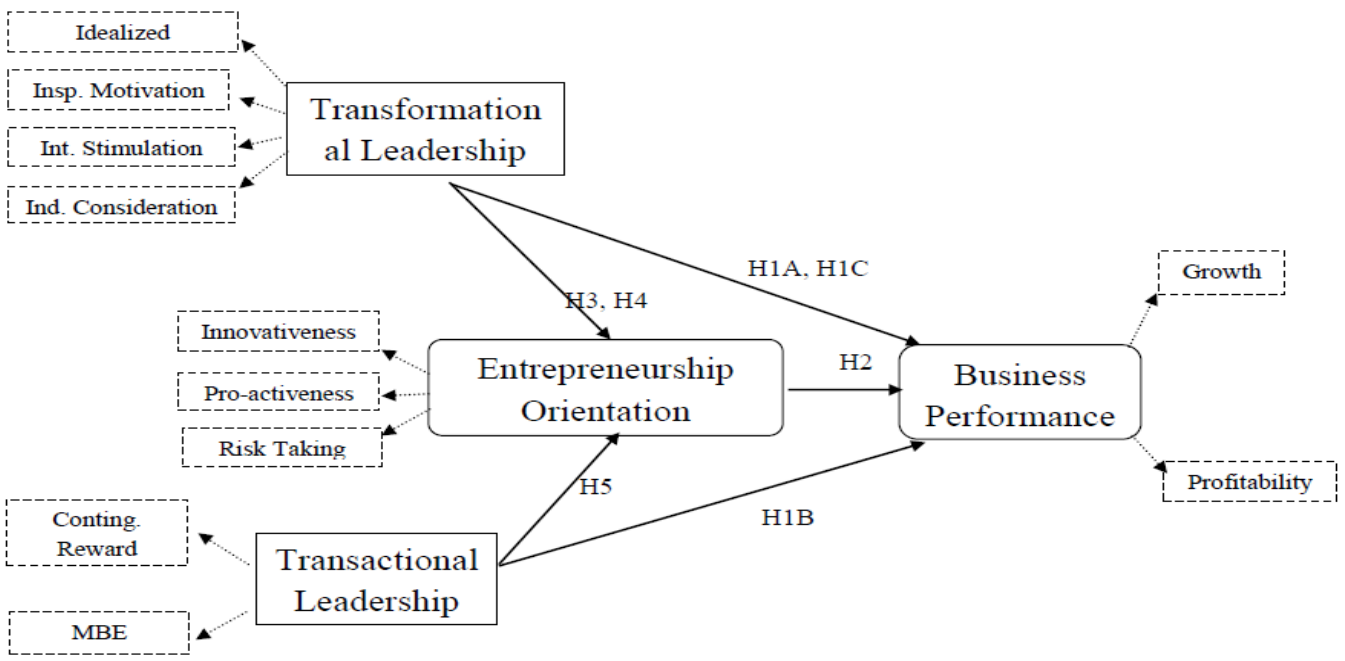

Figure 1. Theoretical Framework

\section{Sampling and Administration of Questionnaire}

Stratified judgment sampling method was followed to include sample entrepreneurs from various business strata of population. Business stratification was based on the SMEs ownership considering the type (private limited, partnership, and sole proprietorship) and the nature of business (service, manufacturing, and trading). Also, since the definition of the SMEs does not distinguish between small and medium size businesses based on the number of employees and annual turnover, the researcher has made the distinction in three different parameters, viz. number of employees (excluding family members), annual sales, and total investment to select final sample.

The demographic backgrounds of respondents were also considered during survey. Special attention was paid while collecting responses from Newar, Marwari, Thakali, and Muslim community groups as these communities are considered having higher business orientation. The sample also included Dalits/Silpis as people from this community are often involved in traditional skill based business professions. To get responses from above stratified sample, the researcher also used snowball sampling to include more entrepreneurs from different communities and businesses. Using this method, it became easier to find the required respondents.

The questionnaire was initially translated from English to Nepali, followed by a reverse verification from Nepali back to English to develop it into Nepali version by a team of three M. Phil. scholars and was finally reviewed by one Associate Professor. Before the administration of the questionnaire, a test was carried out by piloting the questionnaire to fifteen prospective respondents. Based on the test, some changes were made to arrive at a final Nepali version of the questionnaire.

The questionnaire was administered in the Pokhara Valley in December, 2016. Survey only included those firms which had at least one full time paid employee excluding the owner and her/his family members, and asked to relate leadership style statements only with owner-employee relationship. Out of 367 questionnaires distributed, a total of 194 were returned, within a week, out of 
which 188 were found usable after verifying with the defined criteria. The response rate was around 53 percent whereas the usability rate was 51 percent. As 175 was the required sample size as per the rule of thumb (5 observations for 1 item) for a questionnaire with 35 items for multivariate analysis (Hair, Black, Babin, \& Anderson, 2010), the final usable questionnaire was thus fit for generalization of results.

\section{Unit of Analysis}

The Questionnaire was addressed to the heads of the SMEs, identified as owners, executive directors, or top-level managers as they are the most informed people about operational and financial activities of their firms. Thus, each individual/owner of the SME was a unit of analysis within this study.

\section{Measures}

In this study, variables studied were transformational leadership, transactional leadership, entrepreneurship orientation, and business performance. The questionnaire comprised self-rated four sections with three validated survey instruments including fourteen items for demographic information. First three sections included three instruments, viz. Multifactor Leadership Questionnaire (MLQ), Entrepreneurship Orientation Questionnaire (EOQ), and Business Performance, which were measured on 5-point Likert scale. Items for all scales used in the study are listed in Appendix. The fourth section included information on demographic characteristics.

The first section of the questionnaire was based on the MLQ 6S. The MLQ is the most widely utilized instrument for measuring transformational and transactional leadership styles (Bass, 2008). Only eighteen out of twenty-one items of MLQ 6S representing transformational and transactional leadership have been included in the questionnaire. The three items representing laissez-faire leadership style were excluded in the questionnaire as it was not studied in this research. Uprety (2016) reported 0.61 and 0.71 overall Cronbach's alpha for transactional and transformational leadership respectively whereas Shrestha (2012) reported 0.74 and 0.92 for them in Nepal.

The second section of the questionnaire was based on the EOQ. The EOQ is one of the most widely used instruments to measure entrepreneurship orientation. Covin and Slevin (1989) developed this instrument based on the earlier study of Khandwalla (1977) and Miller (1983). The EOQ contains three dimensions of EO (innovation, proactiveness, and risk taking) with three items on each dimension. The Cronbach's alpha coefficient for overall EO ranged from 0.72 (Arham, 2012) to 0.87 (Yang, 2008).

The third section of the questionnaire was related with business performance scale. The measure contains eight items scale adopted from Arham (2012). Each four items are related to perceived growth and profitability of the firm. The scale with growth dimension was adopted as the SMEs profitability does not require to be made public and owners are reluctant to provide actual financial figures. Arham (2012) reported 0.80 as Cronbach's alpha for overall business performance variable.

The fourth section of the questionnaire was intended to collect demographic data. It included age, gender, education, ethnicity, and position of respondents as well as age, size, type, and nature of firm.

\section{Data and Analysis}

Each returned questionnaire was manually screened for missing data and those questionnaires with missing data were discarded during data entry. SPSS 21.0 for Windows statistical software was used for analysis. Descriptive statistics was used to check the error on coding and entering the data through dispersion, central tendency and normality. 
The gathered responses include diversity on characteristics of the SMEs (e.g., size, nature, type, age, etc.) and demographic characteristics (e.g., gender, age, ethnicity, educational level, etc.) of the respondents. The firm's characteristics of respondents showed that 27.1 percent have more than ten million (rupees) annual sales, 16 percent has more than ten million investments, 16 percent with above ten employees and considered as medium level enterprises for this study. The remainders of the businesses were considered small level enterprises. The sample contained mostly from proprietorship business (68.6 percent) compared to other types of business (Private limited firms, 25.5 percent, Partnership, 5.9 percent). Out of total usable samples, the service (45.2 percent) and trading (43.6 percent) nature businesses were nearly equal whereas only 11.2 percent were manufacturing business. Majority of the respondents were male ( 88.5 percent), owners of the business ( 94.1 percent), have educational qualification bachelors or above (58 percent), and with age above thirty years (77.4 percent). Only about 30 percent of the responded firm's age was less than five years, whereas about 55 percent were from within 5-20 years' age category, and rests of the businesses were from above twenty years' age category. The gathered responses were also from different ethnic groups (Newar, 22.9 percent, Marwari/Madhesi, 2.5 percent, Janajati, 7.4 percent, Bramin/Chhetri, 59.6 percent, Dalit Community, 5.9 percent, and Muslim Community, 1.7 percent).

\section{Reliability Analysis}

Reliability analyses for each instrument were carried out by calculating Cronbach's alpha (CA) and has been presented in Table 1. The alpha consistency for transformational leadership and business performance was above 0.74 indicating good internal consistency. The EO instrument's CA was 0.69, which was very close to the 0.7 basic standards for internal reliability whereas transactional leadership's CA was 0.70 after deleting one item out of its six items. Thus, all four instruments viz. transformational leadership, transactional leadership, EO, business performance can be considered as internally reliable, indicating that, they measured the concepts what they intended.

As the data set of all study variables were collected at the same point and the same source, it could lead to common method bias causing systematic measurement errors. To evaluate influence of this bias, Harman's single-factor test was used in this study as recommended by Podsakoff, MacKenzie, and Podsakoff (2012). The subsequent results of factor analysis for all variables were below 50 percent cut-off point, (transformational leadership, 26.58 percent, transactional leadership, 37.78 percent, EO, 29 percent, business performance, 41.52 percent) indicating that dataset didn't suffer from the common method bias.

\section{Results}

After reliability analysis, new composite of transformational leadership, transactional leadership, EO, business performance, and their respective dimensions were calculated as an average score of the items which are on a scale of 1 to 5. The mean score, standard deviation, correlations among the study variables and the reliability coefficients are shown in Table 1. Leadership style and business performance means were above average whereas EO was less than average. The correlation analysis reflects that, all the study variables were significantly correlated with each other except EO and transactional leadership.

Regression analyses were conducted to look into the causal effect of two leadership styles (transactional and transformational) independently on EO and business performance to evaluate hypothesis 1 and 2 and additionally to observe the effect of EO on business performance to evaluate hypothesis 3. The PROCESS (Hayes, 2018) was used to identify mediating role of EO between 
leadership style and business performance and test hypothesis 4 and 5. It was used because historically popular causal steps of Baron and Kenney (1986) for mediation was criticized as 'not ideal both statistically and philosophically' (Hayes, 2018) and was recommended as new method that quantified the indirect effect and required inferential test. The PROCESS output for mediation test (Model 4) presents regression results of independent variable $(\mathrm{X})$ on mediator variable $(\mathrm{M})$, of independent $(\mathrm{X})$ and mediator variable $(\mathrm{M})$ on dependent variable $(\mathrm{Y})$, and of mediator variable $(\mathrm{M})$ on dependent variable (Y). It also presents total effect of X on $\mathrm{Y}$, direct effect of $\mathrm{X}$ on $\mathrm{Y}$, and indirect effect of $\mathrm{X}$ on $Y$ through M. Under this procedure, to mediate, zero should not lie between the indirect effect's 95 percent bootstrap confidence interval. But, if zero lies between indirect effect's confidence interval, it rejects the mediation relationship.

Table 1

Correlation Matrix and Reliability Coefficients of Study Variables

\begin{tabular}{llcccccc}
\hline & & Mean & SD & 1 & 2 & 3 & 4 \\
\hline 1 & Transformational Leadership & 3.97 & .48 & $(0.74)$ & & & \\
2 & Transactional Leadership & 4.06 & .63 & $.61^{* *}$ & $(0.70)$ & & \\
3 & Entrepreneurship Orientation (EO) & 2.86 & .77 & $.19^{*}$ & $.12^{+}$ & $(0.69)$ & \\
4 & Business Performance & 3.61 & .74 & $.27^{* *}$ & $.22^{* *}$ & $.16^{*}$ & $(0.86)$ \\
\hline
\end{tabular}

Note: ${ }^{+} p<0.10,{ }^{*} p<0.05, * * p<0.01$; Cronbach's alpha in the diagonal

\section{Leadership Style and Business Performance}

As per hypothesis, regression results show that, transformational leadership has significant and positive effect on business performance $(\beta=0.27, p=.000)$. ANOVA test $(\mathrm{F}=14.42)$ and significant $\mathrm{p}$ value also verify it. Hence, these results confirm full support for H1A. Similarly, results show that transactional leadership was significantly and positively related to business performance $(\beta=0.22, p=0.00)$ with significant $F$ value (9.25). This indicates full support for H1B. Higher beta coefficient of transformational leadership (0.27) than transactional leadership (0.22) on business performance signifies that transformational leadership has a more positive impact on the business performance than transactional leadership. As beta coefficients indicate the same level of significance, both leadership styles were further reviewed with two constructs of business performance. Regression results show no significant differences between leadership styles on growth. But transformational leadership was significantly and positively related to profit $(\beta=0.21, p=0.00)$ compared to transformational leadership $(\beta=0.17, p=0.02)$. These results show full support for $\mathrm{H} 1 \mathrm{C}$ and help to conclude that transformational leadership may have a more positive impact on the business performance than transactional leadership.

\section{Entrepreneurship Orientation and Business Performance}

It was proposed that $\mathrm{EO}$ has significant and positive effect on business performance. Regression of EO on business performance shows that, EO was related significantly $(p=0.03)$ and positively $(\beta=0.16)$ to business performance. ANOVA test also verify it $(\mathrm{F}=4.91, p=0.03)$. These results indicate full support for $\mathrm{H} 2$.

\section{Leadership Style and Entrepreneurship Orientation}

It was hypothesized that transformational leadership would have a significant positive relationship to EO than transactional leadership. Results indicated the beta estimate and p-value of transformational leadership $(\beta=0.19, p=0.01)$ was positive and significant as well as with significant $F$ value (6.65). The 
beta estimate of transactional leadership $(\beta=0.12)$ was positive but only significant at 0.09 with small $\mathrm{F}$ value (2.86). Comparison between these two results confirms full support for $\mathrm{H} 3$.

\section{Mediating role of Entrepreneurship Orientation}

It was proposed that EO would mediate the relationship between both leadership style (transformational and transactional) and business performance. First, mediating effects of EO on the relationship between transformational leadership and business performance was assessed. The PROCESS results indicated that total effect of transformational leadership on business performance was $0.41(\mathrm{CI}=.20$ to $.63 p=0.00)$. Out of total effect, the direct effect of transformational leadership on business performance was $0.381(\mathrm{CI}=.16$ to $.60, p=0.00)$. The indirect effect of transformational leadership on business performance through EO was 0.03 . The confidence interval of indirect effect shows that zero does not lie between the bootstrapping lower and upper confidence interval (CI=.001 to .10). These signify that EO mediates both relationships and supports for H4.

Lastly, mediating effects of EO on the relationship between transactional leadership and business performance was assessed. The PROCESS results indicated that total effect of transactional leadership on business performance was $0.255(\mathrm{CI}=.090$ to $.421 \mathrm{p}=0.00)$. Out of the total effect, the direct effect of transactional leadership on business performance was $0.236(\mathrm{CI}=.070$ to $.401, p=0.00)$. The indirect effect of transactional leadership on business performance through EO was 0.02. But, the indirect effect's confidence interval shows that zero lies between the bootstrapping lower and upper confidence interval $(\mathrm{CI}=-.002$ to .071$)$. This implies that EO does not mediate transactional leadership and business performance. Hence, H5 was not supported. Regression results of all hypotheses are summarized and given in Table 2 and 3.

\section{Discussion}

This research revealed both transformational and transactional leadership styles exert significant positive influence over business performance and are consistent with the results of Yang (2008). Furthermore, this study demonstrated that transformational leadership style was the strong predictor of EO as well as business performance compared to transactional leadership which was consistent with the previous findings (Arham, 2012; Yang, 2008). These results confirmed that the owners of the Nepali SMEs need to have key aspects of transformational leadership, viz.: idealized influence, inspirational motivation, intellectual stimulation, and individualized consideration for increased EO as well as for higher business performance.

In line with Covin and Slevin (1991), this study also confirmed that EO was positively related to business performance. Consistent with other literature reviewed (Smart \& Conant, 1994; Wiklund \& Shepherd, 2005; Zahra, 1995) the findings from the current study also suggest that high levels of EO contribute positively to business performance. Building on this relationship, Nepali owners can increase their innovativeness, proactiveness, and risk-taking behavior in their SMEs for higher level of business performance.

This study found that EO mediates between transformational leadership and business performance and rejects mediation role of EO between transactional leadership and business performance. These results were consistent with Arham (2012). Hence, empirical findings based on Nepali SMEs owners indicate that, if transformational leadership is practiced, it exerts stronger effects on EO, which in turn raises performance than transactional leadership does. Thus, in line with previous studies (Arham, 2012; Yang, 2008), this study supports that entrepreneurs need to follow transformational leadership 
style for higher performance and also argues the idea of entrepreneurial leadership (Gupta et al., 2004; Paudel, 2019), which is viewed to be more transformational than transactional in nature.

Table 2

Regression Results for testing $\mathrm{H1}, \mathrm{H} 2$, and $\mathrm{H3}$

\begin{tabular}{|c|c|c|c|c|c|c|c|c|c|}
\hline $\mathrm{X} \downarrow$; Y $\rightarrow$ & BP & BP & G & $\mathrm{P}$ & G & $\mathrm{P}$ & $\mathrm{BP}$ & $\mathrm{EO}$ & EO \\
\hline TFL & $0.27 * *$ & & $0.29 * *$ & $0.21 * *$ & & & & $0.19 * *$ & \\
\hline TSL & & $0.22 * *$ & & & $0.22 * *$ & $0.17 *$ & & & $0.12^{+}$ \\
\hline EO & & & & & & & $0.16^{*}$ & & \\
\hline $\mathrm{F}$ & $14.42 * *$ & $9.25 * *$ & $17.3 * *$ & $8.3 * *$ & $9.9 * *$ & $6.17^{*}$ & $4.91 *$ & $6.65^{* *}$ & $2.86^{+}$ \\
\hline $\mathrm{R}^{2}$ & 0.07 & 0.05 & 0.08 & 0.04 & 0.05 & 0.03 & 0.03 & 0.04 & 0.02 \\
\hline Adj. $\mathrm{R}^{2}$ & 0.07 & 0.04 & 0.08 & 0.04 & 0.04 & 0.03 & 0.02 & 0.03 & 0.01 \\
\hline Results & $\begin{array}{c}\text { H1A } \\
\text { Supported }\end{array}$ & $\begin{array}{c}\text { H1B } \\
\text { Supported }\end{array}$ & & $\begin{array}{r}\mathrm{H} \\
\text { Supp }\end{array}$ & & & $\begin{array}{c}\mathrm{H} 2 \\
\text { upported }\end{array}$ & & rrted \\
\hline
\end{tabular}

Note: ${ }^{+} p<0.10,{ }^{*} p<0.05,{ }^{*}{ }^{*} p<0.01 ; \mathrm{X}$ : Independent Variable; Y: Dependent Variable; TFL: Transformational Leadership; TSL: Transactional Leadership; EO: Entrepreneurship Orientation; BP: Business Performance

Table 3

PROCESS Regression Results (Model 4) for testing H4 and H5

\begin{tabular}{|c|c|c|c|c|c|c|}
\hline & \multicolumn{3}{|c|}{$\mathrm{H} 4(\mathrm{TFL}(\mathrm{X}) \rightarrow \mathrm{EO}(\mathrm{M}) \rightarrow \mathrm{BP}(\mathrm{Y}))$} & \multicolumn{3}{|c|}{$\mathrm{H} 5(\mathrm{TSL}(\mathrm{X}) \rightarrow \mathrm{EO}(\mathrm{M}) \rightarrow \mathrm{BP}(\mathrm{Y}))$} \\
\hline & Total & Direct & Indirect & Total & Direct & Indirect \\
\hline & Effect & Effect & Effect & Effect & Effect & Effect \\
\hline Effect & .4142 & .3814 & .0328 & .2552 & .2356 & .0196 \\
\hline SE & .1091 & .1106 & .0242 & .0839 & .0840 & .0170 \\
\hline $\mathrm{P}$ & .0002 & .0007 & & .0024 & .0056 & \\
\hline LLCI & .1990 & .1632 & .0010 & .0896 & .0699 & -.0016 \\
\hline ULCI & .6294 & .5995 & .1017 & .4208 & .4013 & .0707 \\
\hline
\end{tabular}

\begin{tabular}{lcc}
\hline $\begin{array}{l}\text { Hypothesis } \\
\text { Results }\end{array}$ & H4 & H5 \\
Supported & Not Supported \\
\hline
\end{tabular}

X: Independent Variable; Y: Dependent Variable; M: Mediating Variable; TFL: Transformational Leadership; TSL: Transactional Leadership; EO: Entrepreneurship Orientation; BP: Business Performance; L/ULCI: Lower/Upper Level Confidence Interval

\section{Implications}

The findings of this research will have both research and practical implications. Basically, it shall provide valuable knowledge on entrepreneurship, leadership, and business performance for upcoming researchers and learners. Whereas most of the prior researches in this study area have focused on the developed, especially Western, countries; this research which was carried out in Nepal has empirically verified the usage of these concepts in the context of developing country. This indicates that the measures and the instruments shall be relevant for upcoming researches in developing and least developed countries.

Moreover, the findings of this research shall also be significantly important to the SMEs' owners, educators, and policymakers, who might be interested to understand and implement those findings. The 
findings of this research provided evidence of the SMEs entrepreneurial orientation level in a developing country. The findings will further help understand that the SMEs performance could be enhanced through leadership and EO. This study provides empirical evidences that transformational leadership is the most appropriate leadership style for positive EO which can further improve business performance. The findings of this study can be used as consulting options by Nepali entrepreneurs to enhance their own leadership and entrepreneurship skills and to recruit top management who exhibit these skills or train and develop existing manager's skills for firm's better performance. The educators and universities can also incorporate important findings of this research in their courses, lectures as well as trainings to teach/train to help enhance the business skills of their students. It will also help policymakers, specially the government and the development agencies in formulating effective policies for entrepreneurship development. Practically, they can initiate a specific and more robust training program which may contribute to advance and cultivate proper leadership behaviors along with appropriate entrepreneurial skills of entrepreneurs for increased business performance in addition to sustainability of the Nepali SMEs.

\section{Limitations and Future Research Directions}

This study also has several limitations. Basically, the participants in this study were only from Pokhara Valley of Nepal. Researches on other cities, business sectors, other nations, and different socio-cultural and economic context may give different results. Thus, this research can be further extended by involving participants from other locations, business sectors, and contexts which would be useful and more informative.

Moreover, in this study, all constructs were measured from owner's perceptions. Also, as most of the SMEs refuse to provide their true financial performance; this study was based on self-reported subjective measures. These might encourage performance evaluation bias. Though, statistical analyses of this study revealed no problem associated to common method bias, use of multiple sources (survey with employees to know the owners' leadership styles and EO) to collect data and use of objective measures of outcome variables might provide more valid results.

Besides, the research design is based on cross-sectional design, where the data were collected at the same time. So, any causal relationship can't be inferred from this research. Future researchers therefore, should consider adopting a longitudinal research design to shed light on the changes of these relationships over time and find the direction of causality.

Apart from this, since there are many environmental and other factors that influence leadership, entrepreneurship orientation, and the SMEs' performance and sustainability, this research can be further expanded. The extension can be done by including environmental dynamism and other internal and external situational variables as moderating variables while investigating the leadershipperformance relationship.

In a nutshell, this study has added extant knowledge to interaction among leadership style, entrepreneurship orientation, and business performance along with providing new insights and practical importance of these concepts in the context of the Nepali SMEs. This study also provides indepth theoretical understanding for the upcoming researchers and avails more fine knowledge to increase the SMEs performance which might be significant for entrepreneurship and economic development of a nation. 


\section{References}

Arham, A. F. (2012). The relationship between leadership behavior, entrepreneurship orientation and organizational performance in Malaysian small and medium enterprises. (Doctoral dissertation). Royal Melbourne Institute of Technology University. Retrieved from https://researchbank.rmit.edu.au/eserv/rmit:160765/Arham.pdf

Baron, R. M. \& Kenny, D. A. (1986). The moderator-mediator variable distinction in social psychological research: Conceptual, strategic, and statistical considerations. Journal of Personality and Social Psychology, 51, 1173-1182. http://dx.doi.org/10.1037/0022-3514.51.6.1173

Bass, B. M. (2008). Handbook of leadership: Theory, research, and managerial applications (4th ed). New York: Free Press.

Bushell, B. (2008). Women entrepreneurs in Nepal: What prevents them from leading the sector? Gender and Development, 16(3), 549-564. http://dx.doi.org/10.1080/13552070802465441

Covin, J. G., \& Slevin, D. P. (1991). A conceptual model of entrepreneurship as firm behavior. Entrepreneurship: Critical Perspectives on Business and Management, 3. http://dx.doi.org/10.1177/104225879101600102

Eyal, O., \& Kark, R. (2004). How do transformational leaders transform organizations? A study of the relationship between leadership and entrepreneurship. Leadership and Policy in Schools, 3(3), 21135. http://dx.doi.org/10.1080/15700760490503715

Fairoz, F. M., Hirobumi, T., \& Tanaka, Y. (2010). Entrepreneurship orientation and business performance of small and medium scale enterprises of Hambantota District Sri Lanka. Asian Social Science, 6(3), 34-46. http://dx.doi.org/10.5539/ass.v6n3p34

Gautam, P. R. (2016). Entrepreneurship orientation and business performance of handicraft industry: A study of Nepalese handicraft enterprises. International Journal of Small Business and Entrepreneurship Research, 4(2) 48-63. Retrieved from http://www.eajournals.org/journals/international-journal-of-small-business-and-entrepreneurshipresearch-ijsber/vol-4-issue-2-march-2016/

Ghimire, R. (2011).Micro and small enterprises in Nepal: Prospects and challenges. Journal of Finance and Management Review, 2(2), 257-269. Retrieved from http://www.academia.edu/ 5589600/Micro_and_Small_Enterprises_in_Nepal_Prospects_andChallenges

Gupta, V., MacMillan, I. C., \& Suriec, G. (2004). Entrepreneurial leadership: Developing and measuring a cross-cultural construct. Journal of Business Venturing, 19(2), 241-60. http://dx.doi.org/10.1016/S0883-9026(03)00040-5

Hair, J. F., Black, W. C., Babin, B. J., \& Anderson, R. E. (2010). Multivariate data analysis: A global perspective. New Jersey: Prentice Hall.

Hayes, A. F. (2018). Introduction to mediation, moderation, and conditional process analysis: A regression based approach. New York: The Guilford Press.

Khandwalla, P. N. (1977). Some top management styles, their context and performance. Organization and Administrative Sciences, 7(4), 21-51. Retrieved from http://www.scirp.org/(S(i43dyn45teexjx455qlt3d2q))/reference/ReferencesPapers.aspx?ReferenceI $\mathrm{D}=1813948$

Koontz, H., \& Donnell, C. (1993). Introduction to Management. New York: McGraw-Hill.

Lumpkin, G. T., \& Dess, G. G. (1996). Clarifying the entrepreneurship orientation construct and linking it to performance. Academy of Management Review, 21(1), 135-172. DOI: 10.2307/258632 Northouse, P. G. (2010). Leadership: Theory and Practice, (6th ed.). CA: Sage. 
Markman, G., \& Gartner, W. (2002). Is extraordinary growth profitable? A study of Inc. 500 highgrowth companies. Entrepreneurship Theory and Practice, 27(1), 65-75. DOI: 10.1111/15408520.t01-2-00004

Moktan, S. (2007). Development of small and medium enterprises in Bhutan: Analyzing constraints to growth. South Asian Survey, 14(2), 251-282. http://dx.doi.org/10.1177/097152310701400205.

Miller, D. (1983). The correlates of entrepreneurship in three types of firms. Management Science, 29(7), 770-91. http://dx.doi.org/10.1287/mnsc.29.7.770

Ministry of Finance (2017). Economic Survey 2016/17. Kathmandu, Nepal: Author.

Murphy, G. B., Trailer, J.W., \& Hill, R.C. (1996). Measuring performance in entrepreneurship research. Journal of Business Research, 36, 15-23. http://dx.doi.org/10.1016/0148-2963(95)00159$\mathrm{X}$

Pandey, G. D. (2004). Problems and prospects of SMEs in Nepal. In Dahal, N. \& Sharma, B. (eds.) (2004). WTO Membership: Opportunities and Challenges for SMEs in Nepal (pp. 7-14). Kathmandu, Nepal: SMEDP and SWATEE.

Pant, S. K. (2015). Role of the family in entrepreneurship development in Nepali society. The Journal of Nepalese Business Studies, 9(1), 37-47. http://dx.doi.org/10.3126/jnbs.v9i1.14592

Parker, B. (1988). Moral economy, political economy, and the culture of entrepreneurship in highland Nepal. Ethnology, 27(2), 181-194. Retrieved from http://www.jstor.org/stable/3773627

Paudel, S. (2019). Entrepreneurial leadership and business performance: Effect of organizational innovation and environmental dynamism. South Asian Journal of Business Studies, 8(3), 348369. http://dx.doi.org/10.1108/SAJBS-11-2018-0136

Podsakoff, P. M., MacKenzie, S. B., \& Podsakoff, N. P. (2012). Sources of method bias in social science research and recommendations. Annual Review of Psychology, 63, 539-69. DOI: 10.1146/annurev-psych-120710-100452

Rauch, A., Wiklund, J., Lumpkin, G. T., \& Frese, M. (2009). Entrepreneurship orientation and business performance: An assessment of past research and suggestions for the future. Entrepreneurship Theory and Practice, 33(3), 761-87. http://dx.doi.org/10.1111/j.15406520.2009.00308.x

Shrestha, A. K. (2012). Leadership styles, subordinates' satisfaction with the leader and perceived effectiveness: A study in a Nepali telecommunications company. Occasional Paper No. 5, Kathmandu University School of Management.

Shrestha, B. K. (2015). Business opportunity recognition and development process: A study of Nepalese entrepreneurs. South Asian Journal of Management, 22(4), 7-28. Retrieved from https:/www.researchgate.net/publication/303995051

Smart, D. T., \& Conant, J. S. (1994). Entrepreneurship orientation, distinctive marketing. Journal of Applied Business Research, 10(3), 28-38.

Stogdill, R. M. (1948). Personal factors associated with leadership: A survey of the literature. Journal of Psychology, 25, 35-71.

Tuladhar, J. (1996). Factors affecting women entrepreneurs in small and cottage industries in Nepal opportunities and constraints. Kathmandu: ILO and SIDA.

Uprety, R. (2016). Does chief executive officer (CEO) leadership style matter? An empirical analysis of the relationship among CEO leadership style, job satisfaction and profitability in Nepali financial institutions. Journal of Business and Management Research, 1(2), 1-16.

http://dx.doi.org/10.3126/jbmr.v1i2.15656

Journal of Business and Management Research, July 2020, Vol. 3, No. 1 \& 2 
Villanger, E. (2015). Entrepreneurial abilities and barriers to microenterprise growth: A case study in Nepal. The Journal of Entrepreneurship, 24(2), 115-147. http://dx.doi.org/10.1177/0974927615586888

Yang, C. W. (2008).The relationships among leadership styles, entrepreneurship orientation, and business performance. Managing Global Transitions, 6, 257-275. http://dx.doi.org/10.21512/bbr.v6i3.957

Yukl, G. (2013). Leadership in Organizations. NJ: Prentice Hall.

Wennekers, S. \& Thurik, R. (1999). Linking entrepreneurship and economic growth. Small Business Economics, 13(1).27-55. http://dx.doi.org/10.1023/A:1008063200484

Wiklund, J., \& Shepherd, D. (2005). Entrepreneurship orientation and small business performance: A configurational approach. Journal of Business Venturing, 20(1), 71-91. http://dx.doi.org/10.1016/j.jbusvent.2004.01.001

Zahra, S. A. (1991). Predictors and financial outcomes of corporate entrepreneurship: An exploratory study. Journal of Business Venturing, 6(4), 259-85. http://dx.doi.org/10.1016/0883-9026(91)90019A. 


\section{Appendix: Survey Instruments}

Instrument 1: Multifactor Leadership Questionnaire (MLQ) 6S (Source: http://alrestivo.com)

Eighteen descriptive statements are used to judge how frequently each statement fits with SMEs owner (leader) with their employees and team members. The statements are related to six dimensions of transformational and transactional leadership.

1. I make others feel good to be around me.

2. I express with a few simple words what we could and should do.

3. I enable others to think about old problems in new ways.

4. I help others develop themselves.

5. I tell others what to do if they want to be rewarded for their work.

6. I am satisfied when others meet agreed upon standards.

7. Others have complete faith in me.

8. I provide appealing images about what we can do.

9. I provide others with new ways of looking at puzzling things.

10. I let others know how I think they are doing.

11. I provide recognition/rewards when others reach their goals.

12. As long as things are working, I do not try to change anything.

13. Others are proud to be associated with me.

14. I help others find meaning in their work.

15. I get others to rethink ideas that they had never questioned before.

16. I give personal attention to others who seem rejected.

17. I call attention to what others can get for what they accomplish.

18. I tell others the standards they have to know to carry out their work.

Instrument 2: Entrepreneurship Orientation Scale (Source: Covin \& Slevin, 1991)

\section{Innovativeness}

1. In general, top managers of my firm favour...A strong emphasis on the marketing of tried and true products and services. (vs)A strong emphasis on R\&D, technological leadership, and innovations.

2. How many new lines of products or services has your firm marketed in the past 5 years? No new lines of products or services. (vs) Very many new lines of products or services.

3. Changes in product or service lines have been mostly of a minor nature. (vs) Changes in product or service lines have been usually been quite dramatic.

\section{Pro-activeness}


1. In dealing with its competitors, my firm... Typically responds to actions to which competitors initiate. (vs) Typically initiates actions which competitors then respond to.

2. Is very seldom the first business to introduce new products/services, administrative techniques, operating technologies, etc. (vs) Is very often the first business to introduce new products/services, administrative techniques, operating technologies, etc.

3. Typically seeks to avoid competitive clashes, preferring a 'live-and-let-live' posture. (vs) Typically adopts a very competitive, 'undo-the-competitors' posture.

\section{Risk-taking}

1. In general, the top managers of my firm have... A strong proclivity for low-risk projects (with normal and certain rates of return). (vs) A strong proclivity for high-risk projects (with chances of very high returns).

2. In general, top managers of my firm believe that... Owing to the nature of the environment, it is best to explore it gradually via timid, incremental behavior. (vs) Owing to the nature of the environment, bold, wide-ranging acts are necessary to achieve the firm's objectives.

3. When confronted with decision-making situations involving uncertainty, my firm... Typically adopts a cautious, 'wait-and-see' posture in order to minimize the probability of making costly decisions. (vs) Typically adopts a bold, aggressive posture in order to maximize the probability of exploiting potential opportunities.

Instrument 3: Business Performance Scale (Source: Arham, 2012)

\section{Growth}

1. The growth of our company is above average.

2. Our market shares are increasing faster than those of our competitors.

3. My company is growing steadily for the past three years.

4. Our growth is satisfying.

\section{Profitability}

1. We are satisfied with the return on our investments

2. We have higher return on investment (than our competitors).

3. We are satisfied with our return on sales.

4. In general, my company has achieved a very positive financial outcome. 